\title{
Mortar Based on Dune Sand and Substitute Wood Sawdust: Physico-Mechanical Characterization and Relationship Between Properties in Young Age
}

\author{
Assia Aidoud $^{1 *}$, Messaouda Bencheikh ${ }^{1}$, Nacera Khaldi ${ }^{1}$, Ilyess Mouhamed Ahmed Herga ${ }^{2}$ \\ ${ }^{1}$ Laboratory and Department of Civil Engineering and Hydraulics, University 8 May 1945 of Guelma, BP 401, Guelma 24000, \\ Algeria \\ ${ }^{2}$ Department of Civil Engineering and Hydraulics, University 8 May 1945 of Guelma, BP 401, Guelma 24000, Algeria
}

Corresponding Author Email: aidoud.assia@univ-guelma.dz

https://doi.org/10.18280/acsm.450603

Received: 2 December 2021

Accepted: 27 December 2021

\section{Keywords:}

sawdust, mortar, absorption, porosity, resistance

\begin{abstract}
The South of Algeria is known for these immense sand dunes, which cover part of its territory (Sahara). The main objective of this study is the recovery of sands dune and wood waste (sawdust). The latter, which constitutes a potential source of several environmental and economic problems. The objective of this present work is to characterize the physico-mechanical properties at a young age of a dune sand-based mortar lightened by wood waste and to examine the suitability of using it for various applications in the construction of buildings. The improvement of the characteristics of these sands, which essentially formed of sand untapped to date and with the sole aim of enhancing this national sand wealth. The formulation of the mixtures is based on the substitution of dune sand by sawdust, at different weight contents $0,10,20$ and $30 \%$. The quantity of cement is fixed at $450 \mathrm{~g}$. The results obtained show firstly that the introduction of sawdust improves the characteristics of the mixture (grain size tends to be spread out, reduction in densities), and secondly the physico-mechanical characteristics, especially at $30 \%$ substitution (reduction absorption by total immersion of $20.50 \%$, porosity of $28.32 \%$, wet density of $1.73 \%$ and dry density of $14.94 \%$ and increase in tensile strength of $61.43 \%$ and in compression of $63.87 \%$ ). The effect of sawdust on the relationships between the properties of mortars was clearly noted either for the relationships between early strengths or between compressive and tensile strengths.
\end{abstract}

\section{INTRODUCTION}

The evolution of the current world forces us to rethink construction methods. Indeed, today, the construction sector consumes a significant amount of energy. It is responsible for about a quarter of carbon dioxide emissions, not to mention the depletion of non-renewable resources. This sector must therefore innovate to limit its impact on the environment while guaranteeing user comfort [1]. Several investigations have been attempted with the aim of using overabundant sand from the dunes in the construction sector, particularly in Algeria and Africa, which have been the subject of research [2].

The universal need to protect the environment and manage natural resources well requires establishing new laws and adapting new concepts. The recovery of natural materials and the recycling of waste are an effective means in the face of the economic and ecological constraints of recent years [3]. Faced with the context of environmental protection and like all industrial and household waste, waste from wood processing industries will have to be recovered and valued [4]. Many products already exist on the market, but knowledge in this field is still limited and studies must be carried out in order to better understand certain mechanisms and improve the properties of these materials [5].

\section{EXPERIMENTAL DETAILS}

The materials used for the preparation of the mixtures and the making of the various mortars are of local origin, whose preliminary characteristics are presented in Table 1. A witness sand mortar and three mortars composed in a manner substituted dune sand (DS) with different percentages of sawdust $(0,10,20$ and $30 \%)$ respectively. With a stabilization treatment of sawdust before mixing the mortar pastes. This treatment consists of soaking the wood residues in water for 24 hours before use, for each composition Table 2 were the subject of this comparative study at young age $(7,14,21$ and 28 days). The tests concerned the determination of some physico-mechanical properties of early-age mortars (porosity, absorption, wet and dry densities, compressive strength, tensile strength). All the tests were carried out on prismatic specimens $(4 \times 4 \times 16) \mathrm{cm}^{3}$. Keep in water after stripping until the days of the test.

The compression and tensile tests (by three-point bending) were carried out respectively by a press of $2000 \mathrm{kN}$ capacity with speeds of $0.5 \mathrm{MPa} / \mathrm{s}$ and by a digital universal mechanical strength testing machine of $50 \mathrm{kN}$ of capacity, load and controlled displacement. The measurements of the physical properties were carried out by a hydrostatic balance precision of $0.01 \mathrm{~g}$. 
Table 1. Physical characteristics of materials

\begin{tabular}{ccccc}
\hline Properties & Unit & Sand & sawdust & Cement \\
\hline $\begin{array}{c}\text { Finess } \\
\text { modulus }\end{array}$ & $(\%)$ & 1.83 & $\begin{array}{c}\text { Very difficult to } \\
\text { achieve because } \\
\text { of its shape }\end{array}$ & - \\
$\begin{array}{c}\text { Sand } \\
\text { equivalent } \\
\text { (visual) }\end{array}$ & $(\%)$ & 96.68 & 47 & - \\
$\begin{array}{c}\text { Sand } \\
\text { equivalent } \\
\text { (piston) }\end{array}$ & $(\%)$ & 88.86 & 90.9 & - \\
$\begin{array}{c}\text { Apparent } \\
\text { density }\end{array}$ & $\left(\mathrm{g} / \mathrm{cm}^{3}\right)$ & 1.425 & 0.087 & 1.12 \\
$\begin{array}{c}\text { Absolute } \\
\text { density } \\
\text { SSB }\end{array}$ & $\left(\mathrm{g} / \mathrm{cm}^{3}\right)$ & 2.629 & 0,156 & 3.16 \\
\hline
\end{tabular}

Table 2. Composition of the mortars studied

\begin{tabular}{ccccc}
\hline Sawdust content (\%) & MS0\% & MS10\% & MS20\% & MS30\% \\
\hline dune sand $(\mathrm{g})$ & 1350 & 1215 & 1080 & 945 \\
Ciment $(\mathrm{g})$ & 450 & 450 & 450 & 450 \\
Water $(\mathrm{g})$ & 270 & 225 & 225 & 225 \\
Sawdust $(\mathrm{g})$ & 0 & 7.085 & 14.17 & 21.26 \\
W/C & 0.6 & 0.5 & 0.5 & 0.5 \\
\hline
\end{tabular}

\section{INFLUENCE OF SAWDUST ON THE PHYSICAL PROPERTIES OF EARLY MORTAR}

The different results of the physical properties are grouped together in Table 3 and illustrated by figures 'Figure 1', 'Figure 2', 'Figure 3 and Figure 4'.

Table 3. Effect of sawdust on the physical properties of mortar at a young age

\begin{tabular}{cccccc}
\hline Properties & Time & $\mathbf{7}$ days & 14 days & 21 days & 28 days \\
\hline Total immersion absorption (\%) & MS0\% & $14,328 \pm 1,188$ & $12,586 \pm 0,267$ & $8,153 \pm 0,075$ & $9,825 \pm 0,170$ \\
& MS10\% & $12,986 \pm 0,174$ & $12,733 \pm 0,406$ & $9,17 \pm 0,085$ & $8,999 \pm 0,662$ \\
& MS20\% & $14,069 \pm 0,113$ & $14,121 \pm 0,189$ & $10,3 \pm 0,243$ & $10,549 \pm 0,047$ \\
& MS30\% & $11,507 \pm 0,836$ & $13,324 \pm 1,306$ & $9,489 \pm 1,699$ & $7,811 \pm 1,273$ \\
Porosity (\%) & MS0\% & $26,932 \pm 1,807$ & $24,266 \pm 0,486$ & $16,528 \pm 0,194$ & $19,603 \pm 0,269$ \\
& MS10\% & $22,114 \pm 0,620$ & $22,107 \pm 0,496$ & $16,413 \pm 0,185$ & $16,421 \pm 0,772$ \\
& MS20\% & $23,991 \pm 0,095$ & $24,265 \pm 0,087$ & $23,461 \pm 7,341$ & $18,644 \pm 0,130$ \\
Wet bulk masses & gS30\% & $19,883 \pm 0,739$ & $21,736 \pm 1,018$ & $16,209 \pm 2,102$ & $14,052 \pm 1,753$ \\
& MS0\% & $1,143 \pm 0,562$ & $1,474 \pm 0,490$ & $1,082 \pm 0,511$ & $1,098 \pm 0,518$ \\
& MS10\% & $1,13 \pm 0,531$ & $1,385 \pm 0,366$ & $1,092 \pm 0,515$ & $1,09 \pm 0,515$ \\
& MS20\% & $1,41 \pm 0,538$ & $1,419 \pm 0,392$ & $1,148 \pm 0,440$ & $1,106 \pm 0,522$ \\
& MS30\% & $1,115 \pm 0,542$ & $1,35 \pm 0,315$ & $1,095 \pm 0,482$ & $1,079 \pm 0,485$ \\
Volume masses dry (g/cm $\left.{ }^{3}\right)$ & MS0\% & $1,882 \pm 0,825$ & $1,928 \pm 0,003$ & $2,027 \pm 0,957$ & $1,996 \pm 0,944$ \\
& $M S 10 \%$ & $1,703 \pm 0,806$ & $1,737 \pm 0,039$ & $1,79 \pm 0,839$ & $1,828 \pm 0,870$ \\
& $M S 20 \%$ & $1,705 \pm 0,815$ & $1,719 \pm 0,018$ & $1,655 \pm 1,031$ & $1,765 \pm 0,831$ \\
& $M S 30 \%$ & $1,732 \pm 0,700$ & $1,64 \pm 0,090$ & $1,724 \pm 0,999$ & $1,809 \pm 0,965$ \\
\hline
\end{tabular}

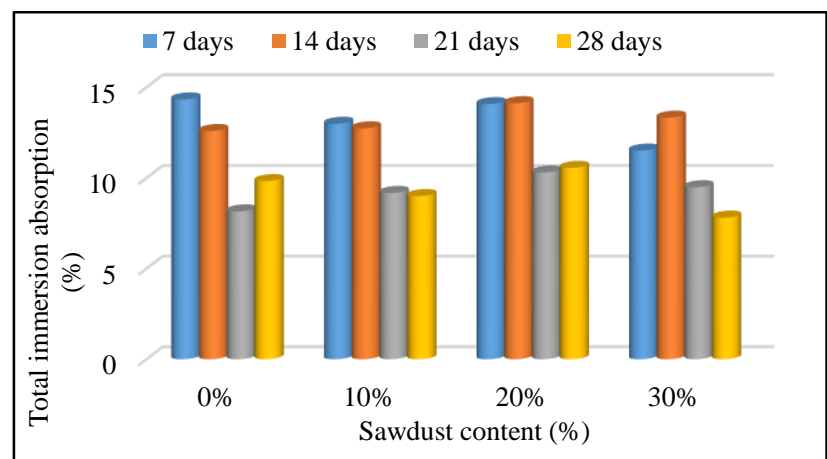

Figure 1. Evolution of immersion absorption as a function of sawdust content at $(7,14,21,28)$ days.

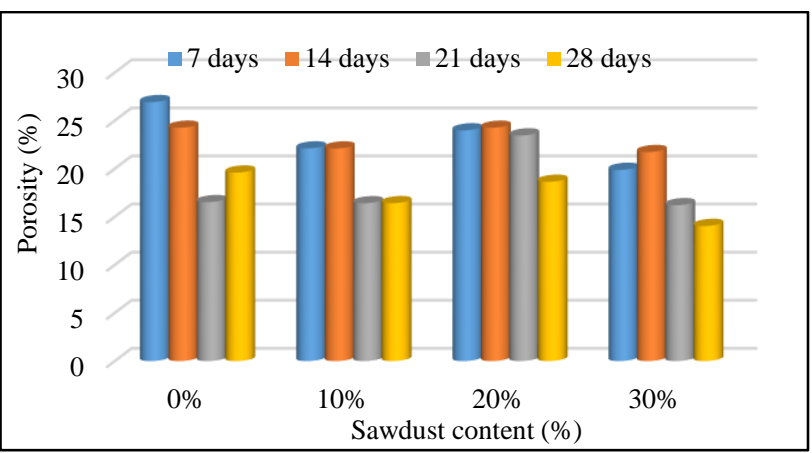

Figure 2. Evolution of porosity as a function of the sawdust content at $(7,14,21,28)$ days

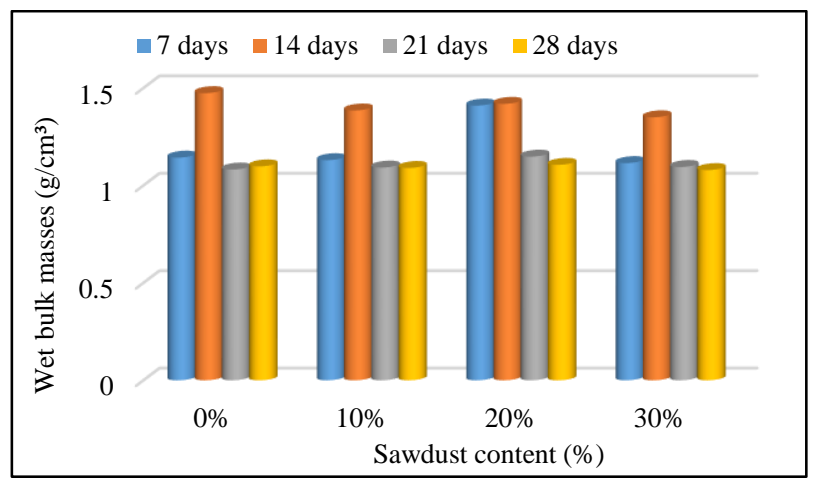

Figure 3. Evolution of the wet densities as a function of the sawdust content at $(7,14,21,28)$ days

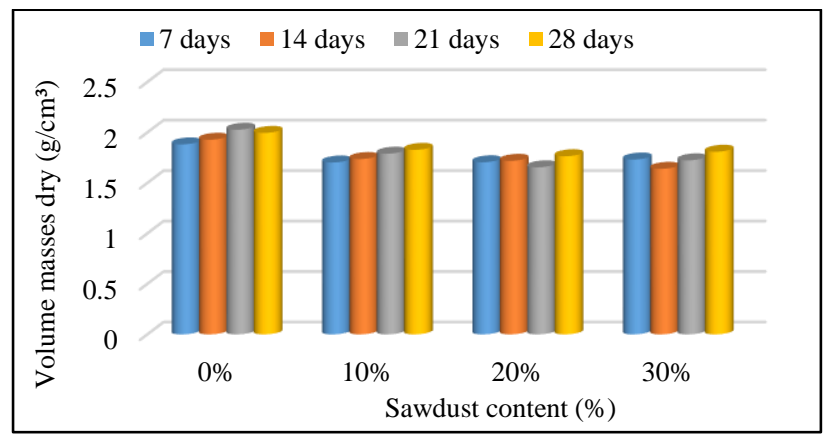

Figure 4. Evolution of dry densities as a function of the sawdust content at $(7,14,21,28)$ days 


\subsection{Total immersion absorption and porosity}

From "Figure 1" MS10\% showed less absorption than $\mathrm{MS} 0 \%$ at 7 and 28 days and moderately greater than $\mathrm{MS} 0 \%$ at days 14 and 21, this decrease in absorption is due firstly to the presence of sawdust with their sizes larger than that of dune sand and secondly to the phenomenon of cement hydration and the composition of ettringites. On the other hand, the absorption of MS20\% is always higher compared to other mortars except at 7 days it marked a slightly less absorption than that of $\mathrm{MS} 0 \%$ at this age. Tend says that MS30\% had the lowest absorption of other mortars at 7 and 28 days and greater than that of $\mathrm{MS} 0 \%$ at 14 and 21 days.

From "Figure 2" MS10\% and MS30\% showed less porosity than $\mathrm{MS} 0 \%$ on days 7-28. While MS20\% scored less porosity than $\mathrm{MS} 0 \%$ at 7 and 28 days to equal it at 14 days and score the greatest porosity at 21 days.

\subsection{Wet and dry density}

From 'Figure 3' The wet density of MS20\% is always higher than those of other mortars except at 14 days it marked a wet density less than that of $\mathrm{MS} 0 \%$ and greater than those of $\mathrm{MS} 10 \%$ and $\mathrm{MS} 30 \%$. MS10\% and MS30\% mortars consistently scored less wet densities than $\mathrm{MS} 0 \%$ and slightly higher than the latter at 21 days.

From "Figure 4" The dry densities of the three mortars (MS10\%, MS20\%, MS30\%) marked consistently lower values than those of MS0\%.

\section{INFLUENCE OF SAWDUST ON THE MECHANICAL PROPERTIES OF EARLY MORTAR}

The various results of the mechanical properties are grouped together in Table 4 and illustrated by figures 'Figure 5 and 6'.

Table 4. Effect of sawdust on the mechanical properties of mortar at young age

\begin{tabular}{cccccc}
\hline Properties & Time & 7 days & 14 days & 21 days & 28 days \\
\hline & MS0\% & $18,782 \pm 6,286$ & $31,697 \pm 5,594$ & $25,085 \pm 4,559$ & $18,033 \pm 2,148$ \\
Compressive & MS10\% & $19,203 \pm 2,687$ & $23,328 \pm 2,267$ & $21,96 \pm 2,655$ & $19,485 \pm 1.643$ \\
strength (MPa) & MS20\% & $20,258 \pm 2,106$ & $24,072 \pm 3,496$ & $22,527 \pm 2,284$ & $20,717 \pm 0.961$ \\
& MS30\% & $24,278 \pm 5,709$ & $17.065 \pm 2.279$ & $24,143 \pm 1,259$ & $29,55 \pm 1.907$ \\
Tensile strength & MS0\% & $4,917 \pm 1,350$ & $6,883 \pm 0,536$ & $4,901 \pm 0,319$ & $3,145 \pm 0,176$ \\
(MPa) & MS10\% & $5,516 \pm 0,616$ & $5,48 \pm 0,236$ & $3,545 \pm 0,614$ & $4,274 \pm 0,434$ \\
& MS20\% & $5,518 \pm 0,125$ & $5,963 \pm 0,107$ & $3,6 \pm 0,860$ & $4,877 \pm 0,131$ \\
& MS30\% & $7,341 \pm 1,166$ & $6,007 \pm 0,841$ & $4,427 \pm 0,794$ & $5,077 \pm 0,669$ \\
\hline
\end{tabular}

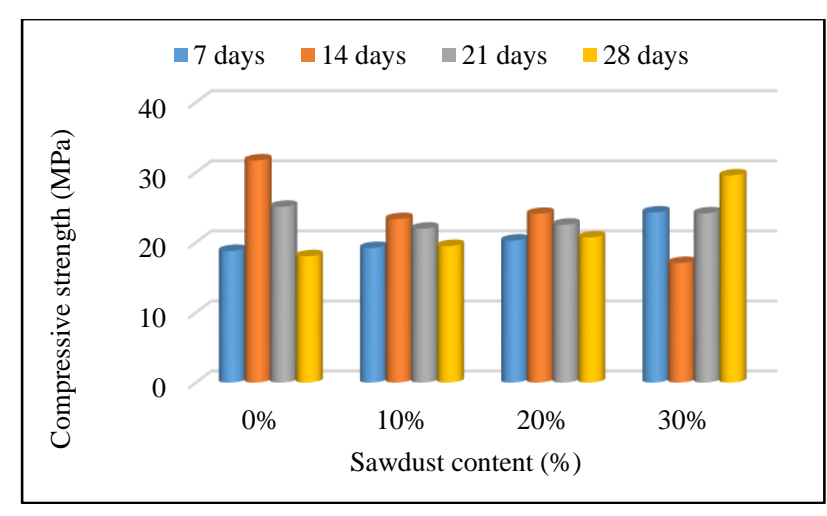

Figure 5. Effect of adding sawdust on compressive strength at $(7,14,21$ and 28$)$ days

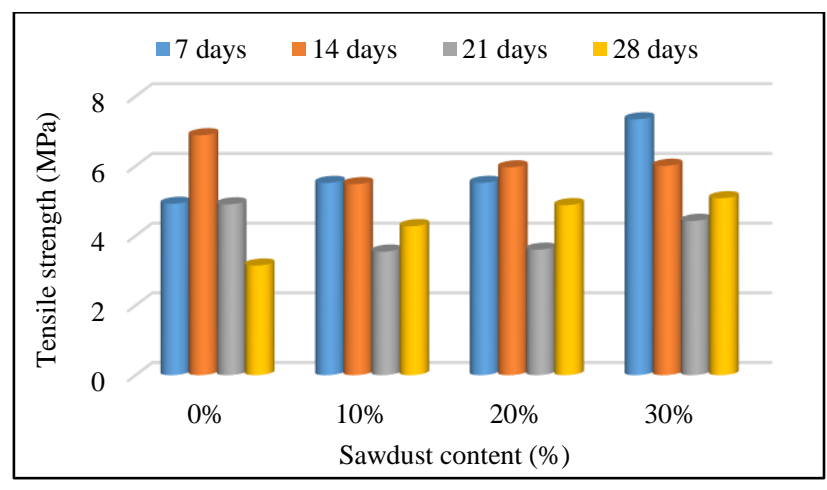

Figure 6. Effect of adding sawdust on tensile strength at $(7,14,21$ and 28$)$ days

\subsection{Résistance à la Compression et à la Traction}

According to 'Figure 5' The pace of the evolution of the compressive strength of mortars (MS10\%, MS20\%) as a function of time is the same with values slightly higher than those of $\mathrm{MS} 0 \%$ to 7 and 28 days, and generally less than 14 and 21 days. On the other hand, that of MS30\% is inversely to that of $\mathrm{MS} 0 \%$ with a remarkable difference at 7 days and very remarkable at 14 and 28 days to mark almost the same resistance at 21 days. The values of the compressive strengths without sawdust or with sawdust show higher values compared to those found by Kameni Kamga [6] because the latter used reverie sand and another method of treating sawdust. On the other hand, my resistance values without less than that of the study by Ndong Engoned [7] that can be explained by its method of treatment by smoothing.

According to 'Figure 6' The pace of the evolution of the tensile strength of the three mortars (MS10\%, MS20\%, $\mathrm{MS} 30 \%$ ) as a function of time is the same with values greater than those of MS0\% at 7 and 28 days and less than 14 and 21 days.

\section{EFFECT OF WOOD WASTE ON THE RELATIONSHIP BETWEEN MORTAR PROPERTIES}

The relationships between early age strengths (compressive and tensile) and characteristic 28 days strengths can be influenced by the substitution of sand by sawdust. It has been observed through the results of these properties that they can present different values. In this part of the work, we explore the effect of sawdust content on these relationships at different ages, for compressive strengths and even for tensile strengths. These relationships between resistances are also situated in relation to those given by the regulations in force (BAEL [8], EC2 [9]).

$\checkmark$ For the relationships between the compressive strengths at a young age and the characteristic 
strengths at 28 days, the following formulas Eq (1) were used; $\mathrm{Eq}(2)$ and $\mathrm{Eq}(3)$ :

From « BAEL $[8]$ »

$$
\mathrm{f}_{\mathrm{Cj}}=\frac{\mathrm{j}}{4,76+0,83 \mathrm{j}} \mathrm{f}_{\mathrm{C}_{28}}
$$

For $\mathrm{f}_{\mathrm{c} 28} \leq 40 \mathrm{MPa}$

From « EC2 [9] »

$$
\mathrm{f}_{\mathrm{cm}}(\mathrm{t})=\beta_{\mathrm{cc}}(\mathrm{t}) \mathrm{f}_{\mathrm{cm}}
$$

With $\quad \beta_{c c}(t)=\exp \left[s\left[1-\left(\frac{28}{t}\right)^{1 / 2}\right]\right]$

Or

"s": is a coefficient which takes different values depending on the class of the cement, in which it is taken equal to 0.25 for our case (Cement CEM $42.5 \mathrm{~N}$ ).

" $f_{\mathrm{cm}}$ ": Average compressive strength at 28 days.

$\checkmark$ And in the same way for the relations between tensile strengths at young age and characteristic strengths at 28 days.

$\checkmark \quad$ For the relationships between compressive strengths and tensile strengths $\mathrm{Eq}$ (4) and $\mathrm{Eq}$ (5).

From « BAEL $[8]$ »

$$
\mathrm{f}_{\mathrm{tj}}=0,6+0,06 \mathrm{f}_{\mathrm{Cj}}
$$

From « EC2 $[9] »$

$$
f_{t j}=0,30(f \mathrm{fj}){ }^{2 / 3}
$$

\subsection{Relationships between compressive strengths at young age and characteristic strengths at 28 days}

The results are grouped together in the Table 5 below and

\begin{tabular}{|c|c|c|c|c|}
\hline Sawdust content & $0 \%$ & $10 \%$ & $20 \%$ & $30 \%$ \\
\hline $\mathrm{Cs}_{7 \mathrm{~d}}$ & 18,782 & 19,203 & 20,258 & 24,278 \\
\hline Cs7d (BAEL) & 11,902 & 11,452 & 12,223 & 16,779 \\
\hline $\mathrm{Cs}_{\mathrm{Sd} \mathrm{d}}(\mathrm{EC})^{\prime}$ & 14,764 & 14,176 & 15,111 & 20,744 \\
\hline $\mathrm{Cs}_{14 \mathrm{~d}}$ & 31,697 & 23,328 & 24,072 & 17.065 \\
\hline $\mathrm{Cs}_{14 \mathrm{~d}}$ (BAEL) & 15,413 & 14,830 & 15,775 & 21,655 \\
\hline $\mathrm{Cs}_{14 \mathrm{~d}}(\mathrm{EC})$ & 16,599 & 15,972 & 16,990 & 23,323 \\
\hline & 23,418 & 19,352 & 15,527 & 24,143 \\
\hline $\mathrm{Cs}_{21 \mathrm{~d}}$ (BAEL) & 17,066 & 16,420 & 17,467 & 23,978 \\
\hline $\mathrm{Cs}_{21 \mathrm{~d}}$ (EC) & 17,895 & 16,822 & 17,895 & 24,565 \\
\hline
\end{tabular}
shown diagrammatically in the Figures 7-9, which follow.

Table 5. Compressive strengths at (7,14 and 21) days as a function of sawdust content

The values of the compressive strength at 7 days are higher than those of BAEL [8] and EC2 [9] for the different sawdust contents.

The values of the compressive strength at 14 days are higher than those of BAEL [8] and EC2 [9] except for the sawdust content of $30 \%$.

The values of the compressive strength at 21 days are lower than those of BAEL [8] and EC2 [9] for the sawdust contents of $20 \%$ and $30 \%$ and higher for the other two contents $0 \%$ and $10 \%$, but the most remarkable which is closer for the latter.

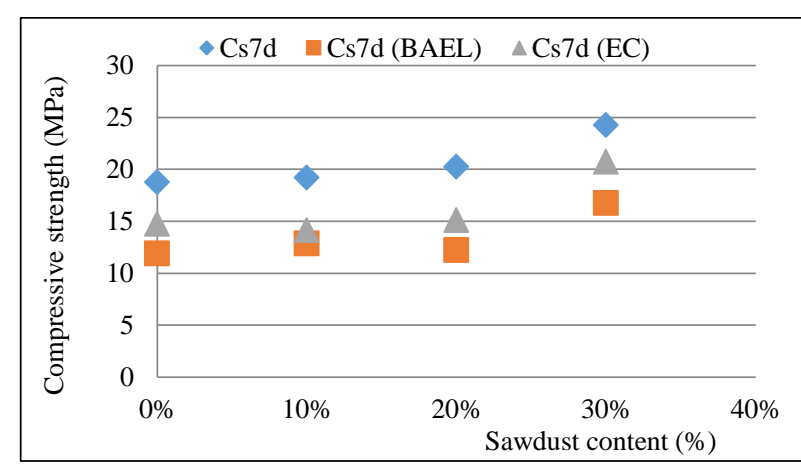

Figure 7. The relationships between the 7-day compressive strengths and the characteristic 28-day strengths as a function of the sawdust content

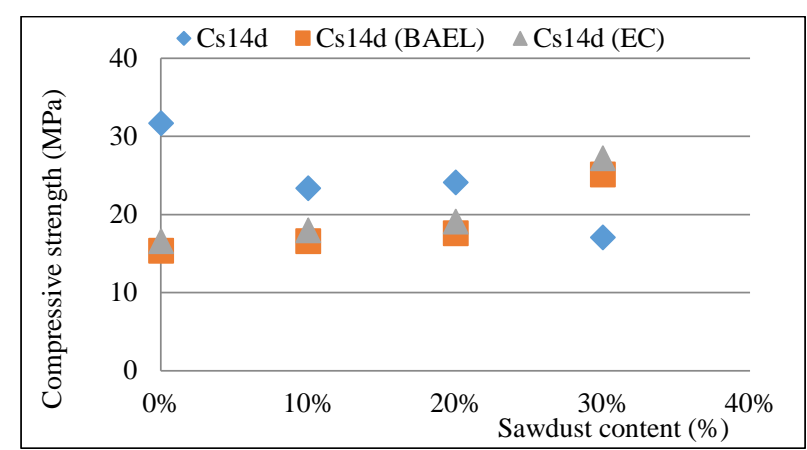

Figure 8. The relationships between the 14-day compressive strengths and the 28-day characteristic strengths as a function of the sawdust content

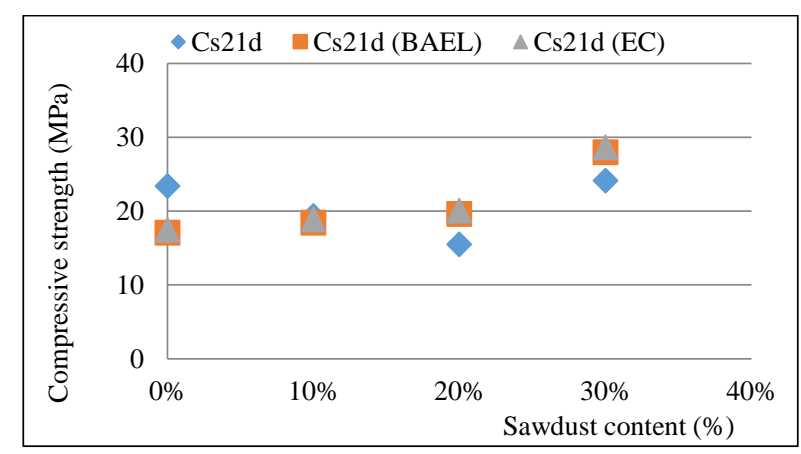

Figure 9. The relations between the compressive strengths at 21 days and the characteristic strengths at 28 days as a function of the sawdust content

\subsection{Relationships between early tensile strengths and characteristic 28-day strengths}

The results are grouped together in the Table 6 below and shown diagrammatically in the Figures 10-12 which follow.

Table 6. Tensile strengths at (7,14 and 14) days as a function of sawdust content

\begin{tabular}{ccccc}
\hline Sawdust content & $\mathbf{0 \%}$ & $\mathbf{1 0 \%}$ & $\mathbf{2 0 \%}$ & $\mathbf{3 0 \%}$ \\
\hline Ts7d & 4,917 & 5,516 & 5,518 & 7,341 \\
Ts7d (BAEL) & 2,076 & 2,821 & 3,219 & 3,351 \\
Ts7d (EC) & 2,575 & 3,499 & 3,993 & 4,157 \\
\hline Ts 14d $_{14}$ & 6,883 & 5,48 & 5,963 & 6,007 \\
Ts14d (BAEL) & 2,673 & 3,633 & 4,145 & 4,315 \\
Ts 14 (EC) & 2,895 & 3,934 & 4,489 & 4,673 \\
\hline Ts 2 21d & 4,901 & 3,545 & 3,6 & 4,427 \\
Ts $_{21 d}$ (BAEL) & 2,975 & 4,043 & 4,614 & 4,803 \\
Ts $_{21 d}$ (EC) & 3,049 & 4,144 & 4,728 & 4,922 \\
\hline
\end{tabular}




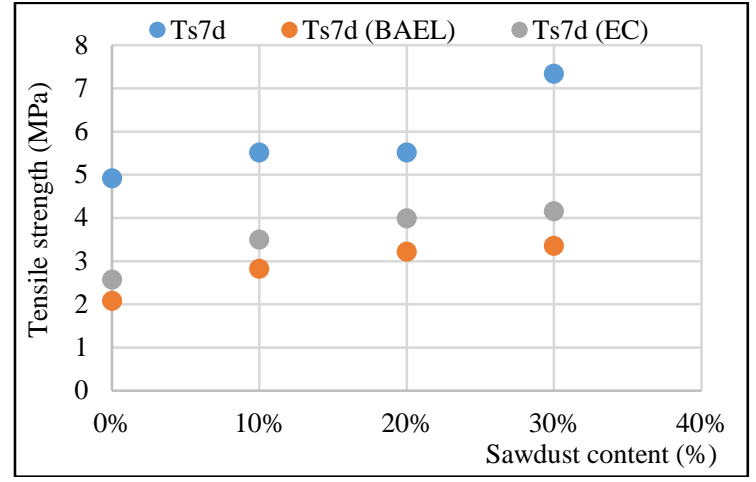

Figure 10. The relationship between the tensile strengths at 7 days and the characteristic strengths at 28 days as a function of the sawdust content

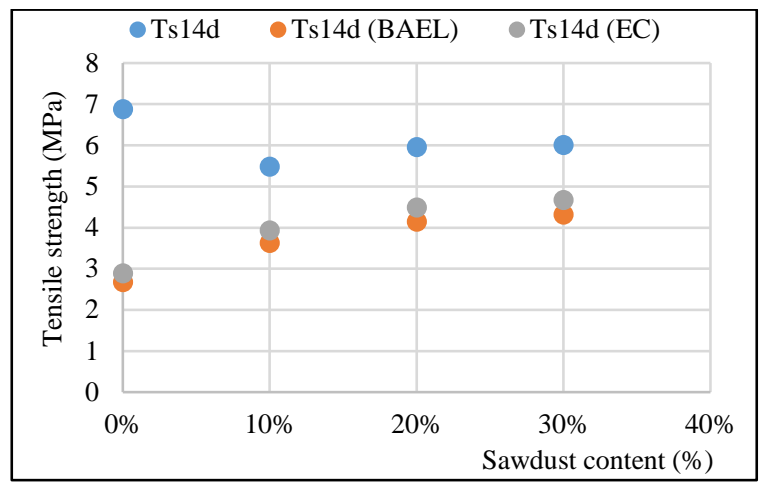

Figure 11. The relationship between the tensile strengths at 14 days and the characteristic strengths at 28 days as a function of the sawdust content

The values of the tensile strength at 7 days are higher than those of BAEL [8] and EC2 [9] for the different sawdust contents.

The values of the tensile strength at 14 days are higher than those of BAEL [8] and EC2 [9] for the different sawdust contents especially at $0 \%$.

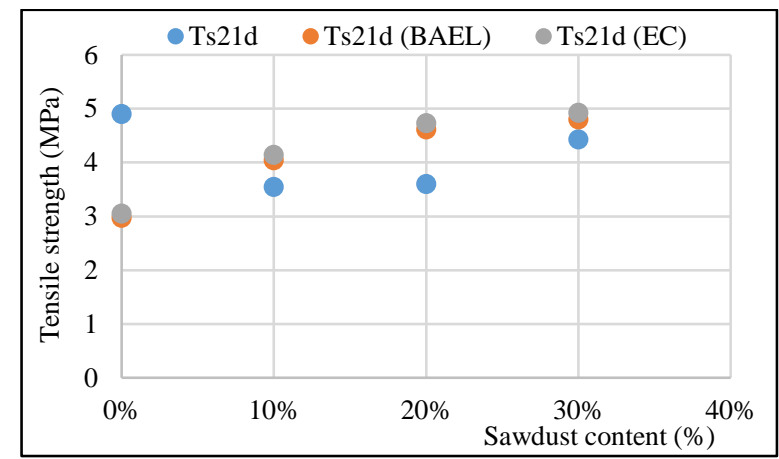

Figure 12. The relationship between the tensile strengths at 21 days and the characteristic strengths at 28 days as a function of the sawdust content

The values of the tensile strength at 21 days are lower than those of BAEL [8] and EC2 [9] for the sawdust contents of $10 \%, 20 \%$ and $30 \%$ and higher for the content $0 \%$.

\subsection{The relationships between compressive strengths and tensile strengths}

The results are grouped together in the Table 7 below and shown diagrammatically in the Figures 13-16 which follow.

The curves for the experimental results are trend lines. And the curves of the results calculated by the formulas of BAEL and EC2 are curves following these formulas.

Table 7. Compressive and tensile strengths as a function of sawdust content at $(7,14,21$ and 28$)$ days

\begin{tabular}{cccccc}
\hline Age & Sawdust content & $\mathbf{0 \%}$ & $\mathbf{1 0 \%}$ & $\mathbf{2 0 \%}$ & $\mathbf{3 0 \%}$ \\
\hline \multirow{6}{*}{7 jours } & Cs (MPa) & 18,782 & 19,203 & 20,258 & 24,278 \\
& Ts (MPa) & 4,917 & 5,516 & 5,518 & 7,341 \\
& Ts (BAEL) & 1,727 & 1,752 & 1,815 & 2,057 \\
& Ts (EC 2) & 2,120 & 2,151 & 2,229 & 2,515 \\
\hline \multirow{6}{*}{ jours } & Cs (MPa) & 31,697 & 23,328 & 24,072 & 17,065 \\
& Ts (MPa) & 6,883 & 5,480 & 5,963 & 6,007 \\
& Ts (BAEL) & 2,502 & 2.000 & 2,044 & 2,041 \\
& Ts (EC 2) & 3,005 & 2,449 & 2,501 & 2,497 \\
\hline \multirow{6}{*}{21 jours } & Cs (MPa) & 23,418 & 19,352 & 15,527 & 24,143 \\
& Ts (MPa) & 4,901 & 3,545 & 3,600 & 4,427 \\
& Ts (BAEL) & 2,005 & 1,761 & 1,532 & 2,049 \\
& Ts (EC 2) & 2,456 & 2,162 & 1,867 & 2,506 \\
\hline \multirow{6}{*}{28 jours } & Cs (MPa) & 18,033 & 19,485 & 20,717 & 29,55 \\
& Ts (MPa) & 3,145 & 4,274 & 4,877 & 5,077 \\
& Ts (BAEL) & 1,682 & 1,769 & 1,843 & 2,373 \\
& Ts (EC 2) & 2,063 & 2,172 & 2,263 & 2,867 \\
\hline
\end{tabular}

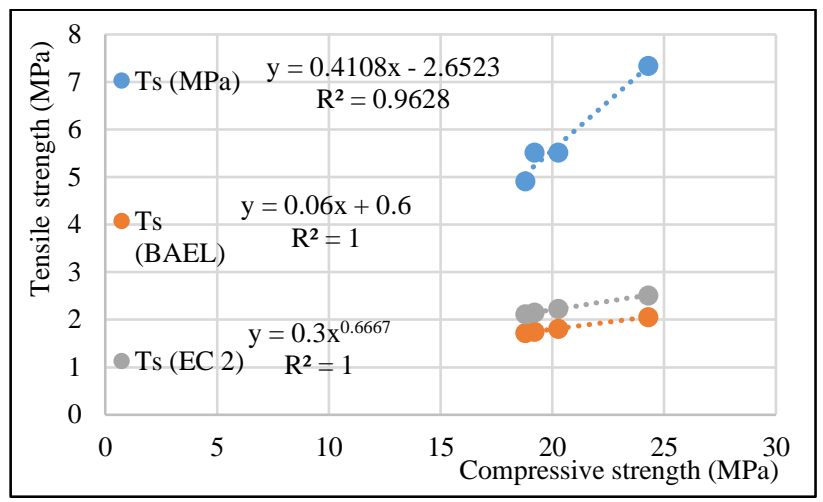

Figure 13. Relationship between compressive strengths and 7-day tensile strengths

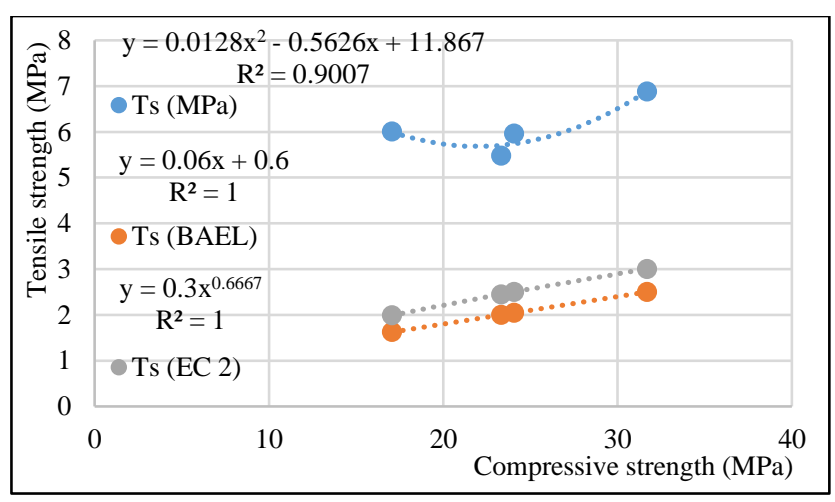

Figure 14. Relationship between compressive strengths and tensile strengths at 14 days

The preceding curves show the Ts-Cs relationships for MSs with different sawdust content $(0 \%, 10 \%, 20 \%, 30 \%)$ at 7,14 , 21 and 28 days. We notice that the differences between the regulatory curves and the experimental curves of the MS are very important with very acceptable regression qualities Ts-Cs $(\mathrm{R} 2=0.9628, \mathrm{R} 2=0.7956, \mathrm{R} 2=0.9007$ and $\mathrm{R} 2=0.9974)$ respectfully at $(7,14,21$ and 28$)$ days. These relationships 
always give overestimated values compared to those of the regulations.

It can be seen that the Rt-Rc relationships are influenced by the sawdust content at different ages.

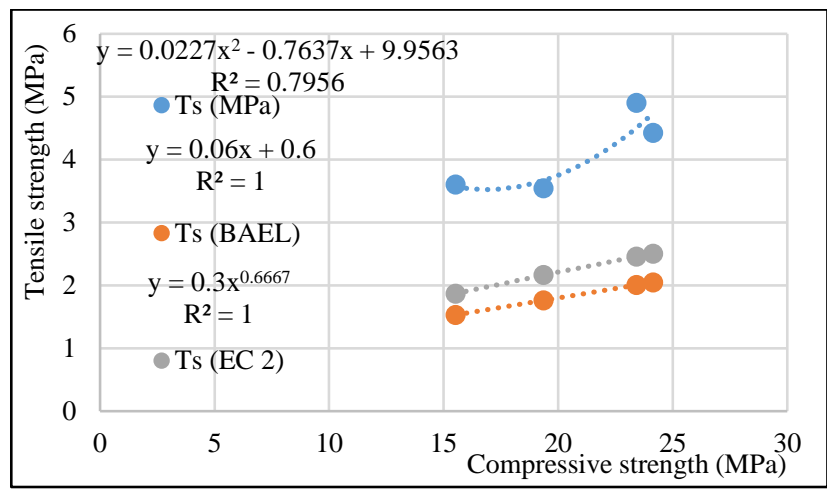

Figure 15. Relations between compressive strengths and tensile strengths at 21 days

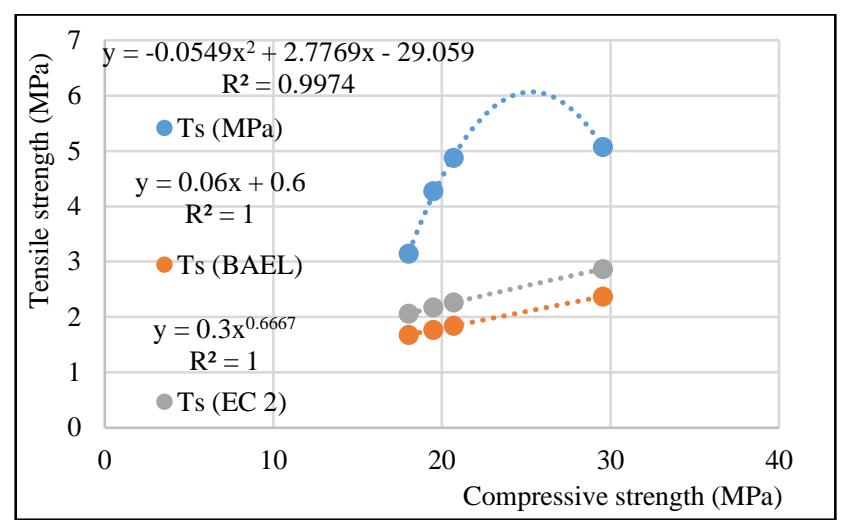

Figure 16. Relationship between compressive strengths and tensile strengths at 28 days

\section{CONCLUSIONS}

The absorption by total immersion has a maximum decrease of the order of $19.69 \%$ compared to MS0\% for (MS30\%) at 7 days, and a gradual increase at 14 and 21 days especially for MS20\% of the order $(12.20 \%$ and $26.33 \%)$ compares to $\mathrm{MS} 0 \%$ and respectively to age. Most notable, at 28 days, was the decrease in total immersion absorption of $\mathrm{MS} 30 \%$ of around $20.50 \%$ compared to that of (MS0\%).

At 7, 14 and 28 days the maximum decrease in porosity was for $(\mathrm{MS} 30 \%)$ respectively of the order of $(26.17 \%, 10.43 \%$, $28.32 \%$ ) compared to (MS0\%). On the other hand at 21 days (MS20\%) marked an unfavorable increase.

The largest decreases in Wet Density were for (MS30\%) on the order of $(2.45 \%, 8.41 \%, 1.73 \%)$ at $(7,14,28$ days $)$ respectively compared to that of (MS0\%).

At 7 days the decreases in Dry Density were almost identical to reach $14.94 \%$ as the maximum values at 14 days for $(\mathrm{MS} 30 \%)$ compared to that of (MS0\%). However, the (MS20\%) marked the maximum values $(18.35 \%, 11.57 \%)$ respectively at (21 and 28 days) compared to that of (MS0\%).

The tensile strength of (MS30\%) increased by almost $50 \%$ compared to that of (MS0\%) at 7 days, and that of (MS20\%) decreased by an order of $(13.37 \%, 27.67 \%)$ respectively at (14 and 21 days) compared to that of (MS0\%), in order to increase for the three mortars $(61.43 \%)$ for (MS30\%) compared to that of $\mathrm{MS} 0 \%$

At 7 days the compressive strength increased in proportion to the sawdust content with an average factor of (1.09), to decrease at 14 days by almost half $(46.16 \%)$ for (MS30\%) of the strength of MS0 \%. At the end it increased by around $(63.87 \%)$ at 28 days compared to that of the MS0\%.

The relationships between the strengths either in tension and in compression at the young age and the characteristic strengths at 28 days are influenced at any age either by values higher or lower than those of the regulations.

The relationships between compressive strengths and tensile strengths are influenced by the sawdust content at different ages.

The correlations between the compressive strengths and the tensile strengths which appear in the regulatory documents (BAEL, EC2) valid for common mortars and concretes are no longer so in our case. Other parameters such as composition and sawdust content as well as age, which have been studied in this work, must be considered in these relationships.

\section{ACKNOWLEDGMENT}

The authors thank the $\mathrm{LGCH}$ research laboratory at the University 8 May 1945 (Guelma) and the pedagogical laboratory of the civil and hydraulic engineering department (Guelma) for their technical support during the experimental work.

\section{REFERENCES}

[1] Akkaoui, A. (2014). Wood aggregate concrete: Experimental and theoretical study of thermo-hydromechanical properties using multi-scale approaches. PhD, University Paris-Est, 231. https://pastel.archivesouvertes.fr/tel-01162671.

[2] Balhachemi, S., Berrafa, F. (2017). Reclamation of dune sand (Naama sand) Durability and mechanical behavior, Master thesis in civil engineering, Belhadj Bouchaib University Center in Ain T'émouchen. http://pmbint.univ-

temouchent.edu.dz/opac_css/doc_num.php?explnum_id $=1082$.

[3] Tsihoarana, H.R., Mamiharijaona, R. (2017). Composite based on pozzolan and sawdust. American Journal of Innovative Research and Applied Sciences, 5(6): 454460.

[4] Raheliarivelo, T. (2004). Contribution to the study of the manufacture of composite materials based on sawdust and Portland cement. Advanced Study Thesis in Materials Science, University of Antananarivo.

[5] Cheumani, Y.A.M. (2009). Study of the microstructure of wood/cement composites by proton NMR relaxometry. Doctoral dissertation, Thesis from the University of Bordeaux 1 (France), 171.

[6] Kameni Kamga, D. (2010). Contribution to the valuation of tropical lignocellulosic by-products in the composition of concrete and mortars (case of parkia biglobosa), Master's thesis, International Institute of Water and Environmental Engineering, University of Ouagadougou. 
[7] Ndong Engoned, JG. (2015). Development of cementitious materials based on wood by-products Shaping by extrusion and vibrocompacting. $\mathrm{PhD}$, Unéversity D'artois.

[8] BAEL 91 rules (DTU P 18-702) (revised February 99, 2000) Technical rules for the design and calculation of reinforced concrete structures and structures using the limit states method Fascicle 62, title 1 of the CCTG Works section 1: reinforced concrete 1 . http://www.sodibet.com/telechargement/BAEL\%2091\% 20R\%2099.pdf.

[9] Eurocode 2 (ENV 1992-1-2): Design of concrete structures, Part 1-2: General rules - calculation of fire behavior. February 2001. http://www-lmdc.insatoulouse.fr/pres/mastergc/telechargement/pedagogie/EC 2_M2P_COAB_Multon_2012.pdf.

\section{NOMENCLATURE}

DS dune sand

$\mathrm{SSB} \quad$ specific surface of Blaine, $\mathrm{cm}^{2} \cdot \mathrm{g}^{-1}$
W/C Water Cement Ratio

MS Mortar with different \% sawdust

f Resistance

s Coefficient which takes different values depending on the class of the cement

t Time (age), days

CEM Portland cement type

Cs Compressive strength, MPa

Ts Tensile strength, $\mathrm{MPa}$

\section{Greek symbols}

$\beta \quad$ Coefficient which takes different values depending on the time (age)

\section{Subscripts}

cj Compressive at ' $\mathrm{j}$ ' days

$\mathrm{c}_{28} \quad$ Compressive at '28' days

tj Tensile at ' $\mathrm{j}$ ' days

$\mathrm{cm}$ Medium compressive 